\section{Origen, desarrollo y crítica de la prosperidad}

\author{
Arturo Piedra Solano*
}

\section{RESUMEN:}

Este trabajo analiza el significado y evolución de la corriente neoprotestante llamada Teología de la prosperidad. La define como una interpretación de la fe cristiana, que percibe las situaciones humanas de enfermedad y pobreza material como resultado de una relación deficiente con Dios. Su sustrato ideológico histórico está vinculado al idealismo y optimismo filosófico estadounidense del siglo XIX. Entre las zonas de mayor influencia de esta corriente están Corea y Estados Unidos de Norteamérica. El autor señala como críticas principales. Es una teología de engaño a los sectores sociales humildes, desarrolla una obsesión materialista, crea falsas esperanzas, y subordina la teología al totalitarismo de la productividad.

* Tiene un Doctorado en Teología por la Universidad de Edimburgo, Nueva Escocia. Ha sido profesor de la Universidad Bíblica Latinoamericana. Entre sus últimas publicaciones están: Haciendo teología en América Latina, Juan Stam, un teólogo del camino; La misión latinoamericana en perspectiva histórica, Evangelización Protestante en América Latina

Rec. 17-10-2005. Aprob. 20-2-06

\section{PALABRAS CLAVE:}

Teología de la prosperidad. Corriente neoprotestante. Teología paralela. Sustrato ideológico. Zonas de influencia.

\section{ABSTRACT:}

This work analyzes the meaning and evolution of the Neoprotestant doctrine called Prosperity Theology. It is defined as an interpretation of the Christian faith that perceives human situations of illness and material poverty as a result of a faulty relationship with God. Their historicalideological substratum is linked to the USA philosophical idealism and optimism of the 19th century. This doctrine has a great impact in areas such as Korea and the United States of America. The author points out as main criticism: It is a theology of deception to the humble social sectors; it develops a materialistic obsession and it creates false hopes and subordinates the theology to productivity totalitarianism.

\section{KEY WORDS:}

Prosperity theology. Neoprotestant doctrine. Parallel theology. Ideological Substratum. Influence areas.

\section{INTRODUCCIÓN}

Puede parecer raro encontrarse con una expresión que a simple vista puede evocar impresiones positivas, pero que tan pronto se analiza, uno se percata de que está rodeada de connotaciones negativas. Esto se aplica al uso en ambientes religiosos del término prosperidad. ¿Quién podría imaginarse que prosperidad sea una palabra de semántica negativa? 
Si las naciones anhelan prosperidad; si todos nosotros anhelamos prosperidad, (un mundo mejor, una, familia mejor, un trabajo mejor, ¿por qué entonces este término está asediado por matices negativos?

Todavía se nos hace más difícil asimilar lo negativo del concepto prosperidad, si al término "prosperidad" le añadimos el de "teología" (el discurso, la preocupación sobre Dios). Ya tenemos entonces la construcción "teología de la prosperidad" que es la suma de dos términos, o realidades, inocentes en apariencia, que cuando se unen provocan en el ambiente religioso más reacciones negativas que positivas.

Me temo que no voy a escapar del asedio negativo de la expresión Teología de la Prosperidad (TP), no porque no pueda hablar de prosperidad en términos positivos, (creo que habría muchas razones bíblicas y teológicas para pensar en una teología de la prosperidad de gran significado positivo). El problema es que mi exposición tiene que ver con otro tema: me han pedido que hable de una corriente religiosa que viene tomando fuerza en círculos religiosos, mayormente protestantes, aunque también se expresa en otros ambientes religiosos e incluso del ámbito secular.
En otras palabras, me han sugerido hablar de un lenguaje religioso que ya es parte de una jerga teológica técnica: se trata de esa corriente que se ha dado en llamar por sus críticos como Teología de la Prosperidad, que en América Latina (AL) comienza a ganar terreno a partir de los años 1980s.

Si la presentación de esta noche no llena las expectativas suyas, les anuncio que pueden adquirir información complementaria en varios artículos que he escrito sobre la Teología de la Prosperidad desde enfoques muy diferentes: uno bastante fuerte que he llamado "el rostro posmoderno del protestantismo latinoamericano" (2003) y otro más descriptivo, y si se quiere más condescendiente, que titulé: "teología de la gracia y teología de la prosperidad: El intento inconcluso de la concreción de la fe cristiana" (2004).

Hoy voy a trabajar el tema más en línea con este último enfoque, tratando de percibir la TP como un desafío, y no tanto como una amenaza.

Dadas estas aclaraciones se hace importante expresar lo que entiendo por "teología de la prosperidad". Permítame definirla en dos sentidos que en el fondo son lo mismo. Primero: como una 
corriente religiosa neoprotestante que establece que una buena relación con Dios conduce a una condición de prosperidad material. Segundo: la TP es una interpretación de la fe cristiana que percibe las situaciones humanas de enfermedad y pobreza material como resultado de una relación deficiente con Dios.

La definición de "teología de la prosperidad" es un lenguaje propio de los críticos de esta corriente $\mathrm{y}$ no tanto un lenguaje con el que se identifican quienes promueven este discurso. Sabemos que en círculos religiosos populares hay cierta desconfianza hacia el quehacer teológico como tal. Pero entendemos que todo discurso religioso está fundado, querrámoslo o no, en convicciones teológicas. Por eso es que no está mal la expresión "teología de la prosperidad" para designar una escuela de pensamiento religioso que opera a nivel popular. Es un movimiento que algunos también llaman "evangelio de riqueza, salud y felicidad".1

En principio habría que reconocer que esta teología es parte de un paquete religioso neoprotestante que en ciertas lugares tiene rasgos

1. Cfr. David Kim Sang-Bok, 1996, "A Bed of Roses or a Bed of Thorns", en Evangelical Revue of theology, 20, p. 14. carismáticos y pentecostales y en otros del protestantismo tradicional. El énfasis en la prosperidad no es más que la punta de un iceberg, el lado más visible y atractivo de un paquete, de un popurrí de nuevas doctrinas que incluyen la guerra espiritual, el ministerio quíntuple, el discipulado de los doce, la restauración del culto o liturgia, un programa agresivo de crecimiento de las iglesias, y un movimiento de apóstoles y profetas de nuevo cuño que está dando mucho que hablar en diferentes círculos religiosos protestantes.

\section{Peligro de una caricatura de la Teología de la Prosperidad}

El tema de la "teología de la prosperidad" es un asunto muy comentado en nuestros días, por el atractivo, entre otros factores, que está teniendo entre los sectores populares y en algunos círculos de hombres de negocios. Yo diría que el interés tan grande que ha ganado ha tenido su efecto boomerang, en el tanto que ha promovido la creación de caricaturas de la misma, especialmente si no hay una preocupación real por entender sus fundamentos y las teorías religiosas de sus propagandistas. 
La caricaturas de los movimientos religiosos de arrastre popular son la consecuencia del trabajo con presuposiciones apriorísticas o con especies de crónicas de conclusiones anunciadas.

Esta tendencia a definir la Teología de la Prosperidad sin pasar por el estudio de sus propias fuentes es lo que ha hecho que algunos de sus defensores cuestionen las críticas cargadas de exageraciones y falacias. Por otra parte, sus críticos lamentan que los sesgos que terminan en enfoques caricaturescos no invitan al diálogo y tienden a ser alterofóbicos.

Algunos se quejan que varios estudios críticos de la Teología de la Prosperidad, aparte de que son monológicos, no logran interesar a los aludidos. Lo peor de estas críticas es que exhiben bastante ignorancia de las fuentes de la corriente que cuestionan. ${ }^{2}$

La debilidad de un análisis de la Teología de la Prosperidad basada en presuposiciones y prejuicios fue advertida en uno de los congresos

2. Un ejemplo de ello es el trabajo de Rodolfo Gaede Neto, Laude Erandi Brandeburg y Evandro Jair Meurer, Teologia da Prosperidad e Nova Era. Instituto Ecuménico de Posgrado, San Leopoldo, 1998. Esta monografía carece de fuentes directas tanto de la Teología de la Prosperidad como del movimiento de Nueva Era. que analizó este movimiento en Bolivia en 1999. Allí se reconoció que la ausencia de la parte objetada produce solo resultados parciales: "con pesar reconocemos que evidentemente esta ausencia limitó el diálogo y empobreció las contribuciones sobre este tema" ${ }^{3}$

Es obvio, que se debe escuchar y leer más a quienes promueven esta óptica, aunque sin duda, el liderazgo de este movimiento tiene al parecer suficientes razones para no responder las críticas de sus adversarios, y sobre todo para no acudir a las citas donde se debate el tema.

\section{Teología paralela}

La aparición de esta teología evoca la tensión, a veces ignorada, que siempre ha marcado la historia de la Iglesia Cristiana entre una teología oficial, defendida por las jerarquías eclesiásticas, su clero y sus teólogos, y el pensamiento religioso que nutre las prácticas religiosas y la devoción del creyente común. La Teología de la Prosperidad es parte de esas prácticas religiosas que sostienen la devoción del creyente común.

3. Gregorio Venables, y otros, 1999, Fe y Prosperidad: Reflexiones sobre la teología de la prosperidad. Editorial Lámpara, La Paz, Bolivia, p. 9. 
Es indiscutible que en el cristianismo siempre han operado dos o más iglesias y dos o más teologías paralelas, las cuales mutuamente se han ignorado y excluido. Ha sido propio de la teología oficial, administrada por las jerarquías, buscar, por todos los medios, el control y la exclusión de las teologías que soportan las creencias religiosas populares.

\section{Peso biográfico}

En la teología cristiana siempre ha destacado el peso biográfico de figuras que determinan las teologías oficiales: Agustín, Lutero, Calvino, Ignacio, entre otros. No va a ser diferente en teologías como la que venimos analizando. La teología de la prosperidad también tiene un gran peso biográfico, aunque diferente de la otra teología. No se niega la fuerza e influencia que tienen algunos de sus líderes como K. Hagin. K. Copeland, B. Hinn, J. Wimber, E. Paulk, P. Wagner, entre otros. Desde Kenyon,4 quien es parte de

4. Kenyon, Essek William (1867-1948). Pastor y escritor. Fundador del Instituto Bíblico Dudley, en Massachusetts. Fue un pionero de las predicaciones evangelísticas radiales, y como producto de este ministerio fundó, en 1931, “la iglesia del aire de Kenyon", conocida más tarde como la Iglesia Bautista del Nuevo Pacto. Escribió 16 libros que tuvieron gran influencia en sectores pen- la prehistoria de este movimiento en los años de 1940 y Hagin, se marcó la autoridad de personas fuertes en la teología de la prosperidad.

Esta teología es todo un movimiento religioso que en su forma más visible esta dominado y conducido por "hombres fuertes", por profetas y apóstoles de nuevo cuño.

Sus críticos del sector evangélico consideran incluso que su autoridad los ha puesto "sobre un pedestal de infalibilidad",5 desde el cual amenazan a sus adversarios, ya no inspirados por el poder político, como lo hicieran Agustín y los reformadores protestantes, sino en sus "poderes espirituales". El dominio de "hombres masculi-

tecostales y carismáticos. Sus críticos le cuestionaron sus tendencias cuasi gnósticas en su teología. Stanley M. Burgess and Gary B. McGee, eds. Dictionary of Pentecostal and Charismatic Movement: Gran Rapids, Zondervan, 1988, p. 517 Figuras de la teología de la prosperidad como Kenneth Hagin y Kenneth Copeland reconocen la influencia de las ideas este predicador en sus apreciaciones religiosas. Algunos de los críticos de la teología de la prosperidad -ej. Hannegraaff- sostienen incluso que las ideas de Hagin son en gran medida un plagio de Kenyon.

5. Dave Hunt, Más allá de la seducción: regreso al cristianismo bíblico. Editorial Portavoz, Gran Rapids, Michigan, 1994, p. 41.

Origen, desarrollo y crítica de la prosperidad 
nos" opaca a las pocas mujeres que se destacan dentro del movimiento de Teología de la Prosperidad.

\section{Trasfondo histórico}

El sustrato ideológico de esta teología se liga con el idealismo y optimismo filosófico estadounidense del siglo XIX, aunque su origen formal se desarrolla, más que todo, en los Estados Unidos, principalmente en los cincuentas. En este tiempo fueron vitales las enseñanzas y liderazgo de W. Kenyon, popularizadas pronto por Kenneth Hagin. De hecho, Hagin es, en la actualidad, una de las figuras más respetadas del movimiento y uno de los mayores forjadores, en los Estados Unidos, de promotores de la teología de la prosperidad.

Las raíces de esta teología se relacionan con el marco incomparable del boom económico después de la Segunda Guerra Mundial,6 Posterior a los años sesentas, las ideas del psicólogo Norman Vincent Peale, en especial su libro "El poder del pensamiento tenaz", será de gran influencia en personalidades destacadas de esta teología. Un ejemplo es Robert Schuller, gestor del llamado "pensamiento

6. W. Ward Gasque, 1996, "Prosperity theology of the New Testament" en Evangelical Revue, 20 , p. 40. posibilista", para quien el progreso material individual depende de una actitud mental positiva. ${ }^{7}$

La Teología de la Prosperidad abriga una concepción optimista del ser humano, contrastándose con la clásica concepción de una humanidad atrapada en el pecado original y cuya liberación no puede más que darse más allá de la historia (en el más allá). Aquí la idea de una humanidad redimida y empoderada para lograr todo tipo de metas humanas deja atrás a una humanidad comparada con los gusanos (En referencia a Isaías).

Por otra parte, la Teología de la Prosperidad viene a ser una teodicea en la que se resuelve de una vez y por todas las implicaciones del mal a través de la derrota de Satanás en la cruz del calvario. Dada esta realidad, a la humanidad no le queda más salida, si quiere superar las limitaciones de la

7. El pensamiento posibilista es en esencia la administración de las ideas... Es la separación disciplinada que se hace de los pensamientos negativos de los positivos bajo el siguiente criterio: Pensamientos positivos son aquellos que mantienen un potencial no desarrollado para el bien. Los pensadores imposibilistas instintivamente reaccionan negativamente a una idea de corte posibilista. Ellos impulsivamente demandan razones para lo que debe ser hecho. Ellos rápidamente abortan una idea y la olvidan. En: Robert H. Schuller, Op. Cit. p. 109. 
pobreza y la enfermedad, que apropiarse de su carácter único como persona exitosa y triunfante.

La corriente religiosa de la prosperidad se enmarca dentro de una doctrina muy propagada entre los círculos de la Teología de la Prosperidad: la enseñanza de los "hijos de rey, por medio de la cual se sostiene que el seguimiento y aplicación de las ordenanzas divinas es suficiente para una vida materialmente próspera:

Los hijos del Rey tienen derecho a recibir un tratamiento especial porque gozan de una relación especial viva de primera mano con su Padre celestial, que hizo todas las cosas y sigue siendo dueño de las mismas. $^{8}$

Esta corriente tiene, como es normal, sus detractores en todas partes, pero también tiene defensores, y sobre todo sus seguidores. Es asombrosa la facilidad con que la gente es enrolada en este esquema religioso.

Entre sus promotores está un historiador cristiano, (Dr. Deiros) de trasfondo bautista, que se ha "convertido" (por decirlo de alguna manera a este movimiento) y quien ve a la TP como parte de una "ter-

8. Harold Hill, Irene Burk Harrel, 1977, Como ser un triunfador. Editorial Vida, Miami, FL, p. 33. cera ola", un movimiento neopentecostal que está presente en todas las denominaciones: la primera ola es el pentecostalismo clásico, y la segunda es el movimiento carismático católico romano. ${ }^{9}$

No creo que sectores grandes de la Teología de la Prosperidad estén muy de acuerdo con la idea de Deiros en ubicar al movimiento dentro de líneas pentecostales o neopentecostales, aún carismáticos. Hay grandes iglesias que están de acuerdo con la Teología de la Prosperidad y sin embargo se distancian de los enfoques pentecostales o carismáticos. En América Central están iglesias de este corte, pero no carismáticas, sería la Gran Comisión en Honduras o la Iglesia de Wilow Creek en los EE.UU.

Para otros que ven con buenos ojos este movimiento la Teología de la Prosperidad ha sido una gran oportunidad que ha permitido encontrar en la Biblia lo que era desconocido a los creyentes. $1^{0}$ Por eso es que David Kim SangBok, teólogo coreano crítico de

9. Pablo A. Deiros y Carlos Mraida, Latinoamérica en llamas: Historia y creencias del movimiento más impresionantede todos los tiempos. Editorial Caribe, Nashville, 1994, p. 136.

10. Citado por Young Hoon Lee, 1996, "The case for prosperity theology" en Evangelical Revue of theology, 20, p. 31. 
esta teología, lamenta que este tema se haya dejado "en las manos indisciplinadas de predicadores de la prosperidad".

Otro de los teólogos de la Teología de la Prosperidad ve al movimiento como una sana perspectiva de la fe cristiana que rescata su aporte en la problemática cotidiana de la vida:

La pobreza y la opresión son sufrimientos reales, reales para millones de gente en el mundo.

¿Tiene la salvación, que Jesús ha traído a este mundo, algo que ver con la liberación de estas formas de sufrimiento? ¿O es que esto tiene que ver sólo con “el alma en el más allá", como algunas teologías cristianas han enseñado sobre la base de una mezcla de un dualismo judío escatológico y un dualismo helénico ontológico ${ }^{11}$

Otro de sus promotores ve esta teología de la prosperidad como una fuerte llamada de atención al cristianismo tradicional por ubicar en el más allá, después de la muerte, las bendiciones materiales que prometen las Escrituras. Para este pastor la iglesia cristiana necesita recuperar el enfoque bíblico sobre las bendiciones materiales divinas

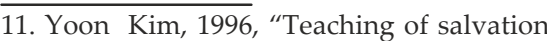
and suffering " en Evangelical Revue of theology, 20, p. 55. que Dios promete otorgar aquí en la tierra y no espacios ultratúmbicos.

En esta misma dirección se refiere otro de sus defensores que atribuyen la la ignorancia en este campo a la mala influencia de una religión que sólo puede ofrecer bienes más allá de la muerte y de la tierra. Observemos el comentario de uno de ellos: "Dios no lo destinó a usted a la miseria, la escasez y la necesidad, Él lo llamó para bendecirlo. Usted debe saber esto. Es imprescindible que lo sepa" ${ }^{12}$

El interés por el bienestar aquí en la tierra, lejos de ser un asunto que avergüence o moleste a estos predicadores, es un hecho aceptado con entera honestidad. No se esconde la opción por "una enseñanza teológica que pone gran énfasis en la prosperidad en la vida presente, más que en la vida que está por venir".$^{3}$ El problema es que no se pasa de una simple retórica, una nueva retórica en la que se cree que se puede obtener prosperidad material por medios mágicos oraciones especiales, pactos económicos, etc. Anticipando

12. Yamil Jiménez, 1997, Dios quiere prosperarte. Pérez Zeledón, Ed. Casa del Banquete, p. 17.

13. C. Kee Hwang, 1996, "A response" en Evangelical Revue of theology. 20, p. 47. 
un juicio de valora: al final el discurso no es más que una mera ilusión para los pobres.

Pero lo que sí se reconoce por los mismos críticos de la Teología de la Prosperidad es que hace falta una teología del sufrimiento que tenga repercusiones inmediatas $y$ cotidianas en el aquí y en el ahora. Por eso es que uno de los participantes en un diálogo que se celebró en Corea pidió que además de la crítica de una teología mala, se tratara de construir una teología de la prosperidad y del sufrimiento que pudiera guiar a los cristianos en su vida cotidiana. ${ }^{14}$

En el fondo de esta observación está el llamado a trascender el marco de la crítica y tratar de responder a las aspiraciones que la gente tiene, aquí y ahora, de una vida digna. Obviamente, se reconoce que, a veces, tenemos más capacidad de criticar que de construir, pero no significa desvalorizar las evaluaciones críticas, sobre todo serias, de un movimiento que levanta muchas preguntas.

Entre los críticos de esta corriente destaca un fuerte sector protestante tradicional. Hay quienes dentro de este sector que no escatiman

\footnotetext{
14. Bon Rin Ro, 1996, "In the Midst of Suffering is Prosperity Theology Scriptural?", en Evangelical Review of Theology, 20, p. 3.
}

palabras para catalogar esta teología de engaño para las personas que atraen. El teólogo Gasque la tilda de engaño para los sectores humildes de la sociedad que buscan salir de sus miserias materiales: "muchos de los pobres que componen las audiencias de estos predicadores, están lamentablemente recibiendo falsas esperanzas, así como muchos con limitaciones físicas están recibiendo falsas esperanzas de una salud perfecta" ${ }^{15}$

Otros han hablado de la obsesión materialista de los cristianos de estos grupos. ${ }^{16}$ Por supuesto que no es nada fácil evadir esta presión en tiempos de tantas limitaciones materiales, especialmente para los más desprotegidos de la sociedad. Por otro lado se impone lo que Brueggemann ha llamado del totalitarismo de la productividad:

sólo valora aquellos que participan en los logros de producción y consumo del consumismo, el cual es gobernado por la triada constituida por dinero, poder y sexo. Las liturgias que sostienen esa ideología son las de los deportes y de la industria de entretenimiento, que se especializa en temas de poder,

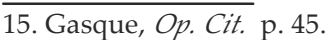

16. Cfr. "Statement on Prosperity Theology and Theology of Suffering", en Evangelical Review of Theology, 1996, 20 , p. 9 . 
éxito, riqueza y placer en formas ilimitadas...No es necesario añadir que esta ideología esconde, y de esa manera la niega, la existencia de aquellos que no son productivos. ${ }^{17}$

\section{Zonas de influencia: Corea y EE.UU.}

La teología de la prosperidad tiene dos zonas de influencia muy definidas. Una es la representada por los predicadores estadounidenses, y la otra proviene de Corea del Sur. De la nación asiática se distingue David Yonggi Cho, fundador en Corea, de la iglesia local más grande del mundo, con más 700000 miembros. Cho creó una filosofía de la prosperidad basada en leyes cuya aplicación comprobada creyó haber demostrado: ley del diezmo, la ley de la siembra y cosecha, la ley del eco.

Dentro del esquema religioso de Cho no cabe la indigencia de muchos cristianos, quienes, para él, actúan como "mendigos perpetuos". $1^{8}$ Los coreanos buscan distanciarse de la percepción de

17. Walter Brueggemann, 2001, "El totalitarismo de la productividad", en Convocados a la Esperanza, Quito, Ed. Seminario Evnagélico de Matanzas y Consejo Latinoamericano de Iglesias, p. 64.

18. David Yonggi Cho, 1996, La cuarta dimensión. Editorial Vida, Miami, Fl, p. 26. la Teología de la Prosperidad que viene de los Estados Unidos por vía de Hagin y otros. Para ellos la versión gringa de la TP no es más que un materialismo económico que no traen beneficios sociales.

Para los coreanos, las deficiencias estadounidenses quedaron claramente manifiestas en los escándalos y caída de los teleevangelistas promotores de la teología de la prosperidad: Jim Bakker y Jimmy Swaggart en los años de la década de $1980 .{ }^{19}$ Es interesante cómo recientes declaraciones de Bakker parecen darle la razón a los coreanos: "engañé a millones de personas que buscaban ganancias materiales, mientras yo -dice Bakkerhabía perdido la verdad de Dios en mi propia vida". Bakker también reconoce que su mensaje religioso fue una especie de "evangelio de Disneylandia". Oigamos una de sus apreciaciones recientes:

Por lo menos hasta la mitad de mi ministerio, yo presenté un evangelio de disneylandia, en el cual la gente buena siempre se hace rica, los malos son derrotados, y después todos viven una vida feliz. Yo viví e intenté promover una tierra de fantasía espiritual en donde la

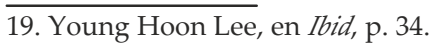


peridad es un fenómeno eminentemente "massmediático" no está lejos de la realidad. Sus críticos les cuestionan su afán y ambición en conseguir emisoras cristianas de televisión, programas y satélites como condición para conquistar espiritualmente el mundo...". ${ }^{23}$

Finalmente, no se puede dejar de reconocer que la crítica a la teología de la prosperidad, tanto en los Estados Unidos como en América Latina, tiene las desventajas o ventajas propias de una reflexión indignada:

Porque las reflexiones indignadas tienen todas las ventajas de lo espontáneo y pasional, y todos los inconvenientes también de lo espontáneo y pasional. Las ventajas son el lenguaje directo, la sinceración sin tapujos, el atrevimiento para decir las cosas sin cálculos de ningún tipo...Las desventajas son la parcialidad, la exageración, la pérdida del sentido de proporción y de la totalidad, las visiones subjetivistas...y la total ausencia del sentido del humor, tan importante en la vida. ${ }^{24}$

23. Dave Hunt y T.A.McMahon, La seduc ción de la cristiandad, Editorial Portavoz, Gran Rapids, Michigan, 1988, p. 231.

24. Felicísimo Martínez, 2002, “¿Nuevas generaciones de teólogos/as?" En Revista Electrónica Latinoamericana de teología (RELAT), 266, p. 1.

\section{BIBLIOGRAFÍA}

Bakker, Jim and Ken Abraham, 1998, Prosperity and the coming apocalipsis: Avoiding the Dangers of Materialistic Christianity in the End Times: Thomas Nelson Publishers, Nashville.

Burgess, Stanley and Gary B. McGee, eds, 1988, Dictionary of Pentecostal and Charismatic Movement: Gran Rapids, Zondervan.

Deiros, Pablo A. y Carlos Mraida, 1994 Latinoamérica en llamas: Historia y creencias del movimiento más impresionante de todos los tiempos. Editorial Caribe, Nashville.

Gaede Neto. Rodolfo, Laude Erandi Brandeburg y Evandro Jair Meurer 1998, Teologia da Prosperidad e Nova Era. Instituto Ecuménico de Posgrado, San Leopoldo.

Hill, Harold, and Irene Burk Harrel, 1977. Como ser un triunfador. Editorial Vida, Miami, FL.

Hunt, Dave y T.A.McMahon, 1988, La seducción de la cristiandad, Editorial Portavoz, Gran Rapids, Michigan.

Hunt, Dave, 1994, Más allá de la seducción: regreso al cristianismo bíblico. Editorial Portavoz, Gran Rapids, Michigan.

Kim, Yoom, 1996, "Teachig on salvation and suffering" En: Evangelical revue of theology, 20.

Venables, Gregorio y otros, 1999, $\mathrm{Fe} y$ Prosperidad: Reflexiones sobre la teología de la prosperidad. Editorial Lámpara, La Paz, Bolivia.

Yonggi Cho, 1996, La cuarta dimensión. Editorial Vida, Miami,Fl, 1996. 